\title{
First Report of Anthelmintic Resistance in Gastrointestinal Nematodes of Sheep from Costa Rica
}

\author{
R. Maroto, ${ }^{1}$ A. E. Jiménez, ${ }^{1}$ J. J. Romero, ${ }^{2}$ V. Alvarez, ${ }^{3}$ J. B. De Oliveira, ${ }^{1}$ and J. Hernández ${ }^{1}$ \\ ${ }^{1}$ Laboratorio de Parasitología, Escuela de Medicina Veterinaria, Universidad Nacional, Costa Rica, P.O. Box 304-3000, \\ Heredia, Costa Rica \\ ${ }^{2}$ Programa de Medicina Poblacional, Escuela de Medicina Veterinaria, Universidad Nacional, Costa Rica, P.O. Box 304-3000, \\ Heredia, Costa Rica \\ ${ }^{3}$ Servicio Nacional de Salud Animal, Ministerio de Agricultura y Ganadería, P.O. Box 11965-1000 San José, Costa Rica
}

Correspondence should be addressed to R. Maroto, maroto_vet@yahoo.es

Received 19 January 2011; Accepted 24 March 2011

Academic Editor: David W. Horohov

Copyright ( $) 2011$ R. Maroto et al. This is an open access article distributed under the Creative Commons Attribution License, which permits unrestricted use, distribution, and reproduction in any medium, provided the original work is properly cited.

\begin{abstract}
As the prevalence and severity of anthelmintic resistance continue to rise, nematode infections in sheep correspondingly reduce the profitability of the sheep industry. In Costa Rica, sheep production systems are increasing in both number and importance. A field trial study was carried out to detect the level of anthelmintic resistance to albendazole and ivermectin in gastrointestinal nematodes (GIN) of sheep from seven farms in Costa Rica. Resistance was determined using the fecal egg count reduction test (FECRT). Three treatment groups were assessed on each farm: control, albendazole, and ivermectin. Haemonchus spp. (71\%), Strongyloides sp. (57\%), and Trichostrongylus spp. (43\%) presented resistance levels to albendazole, whereas Strongyloides sp. (43\%), Haemonchus spp. (29\%), and Trichostrongylus spp. (29\%) were resistant to ivermectin. Haemonchus spp., Strongyloides sp., and Trichostrongylus spp. were the most resistant GIN to both products. This study suggests that frequency of treatment, exclusive chemical control, and visual estimation of animal weight to calculate dosage may contribute to the high levels of anthelmintic resistance that were observed on the farms analyzed herein.
\end{abstract}

\section{Introduction}

Costa Rica is a tropical country located in southern Central America. The country is divided into seven provinces and has two defined periods of rainfall: dry (December-April) and rainy (May-November). The mean annual rainfall is $2500 \mathrm{~mm}$, and the mean annual temperature is $28^{\circ} \mathrm{C}$ [1].

The total population of sheep in Costa Rica is approximately 7000 head and is distributed mainly throughout Guanacaste, Puntarenas, and Alajuela provinces [2]. The majority of flocks are sheep-cattle mixed $(71.4 \%)$ and rotational grazing $(52.4 \%)$ in pastures consisting of Hyparrhenia rufa and Brachiaria brizantha; also, minerals are part of feeding. The most common breeds are Pelibuey $(52.4 \%)$ and Barbados (33.3\%) [2]. The average flock size is 100 sheep.

The number of sheep and flocks has risen because of an increase in the consumption of lamb meat. A 56\% increase in the production of lamb meat in the local abattoir was reported in 2009 [2].
The presence of gastrointestinal parasite in sheep has been reported in Costa Rica, and Haemonchus contortus has been the most important species [2]. Only one previous study has evaluated the anthelmintic efficiency of levamisole and thiabendazole in sheep [3]. Because of an observed loss of efficacy of some products in parasite control, sheep farmers and veterinarians have suspected development of anthelmintic resistance (Montero, 2004; personal communication). The objective of the present study was to assess the level of gastrointestinal nematode (GIN) anthelmintic resistance in sheep from Costa Rica.

\section{Materials and Methods}

Seven farms (385 animals), located in Guanacaste (A, B), Puntarenas (C, D), Heredia (E), Alajuela (F), and Limón (G), were used to assess GIN anthelmintic resistance using the fecal egg count reduction test (FECRT). 
TABLE 1: Gastrointestinal nematode egg count percent reduction after treatment with albendazole in seven flocks from Costa Rica.

\begin{tabular}{|c|c|c|c|c|c|c|c|c|}
\hline \multirow{2}{*}{ Farm } & \multicolumn{2}{|c|}{ Control } & \multicolumn{2}{|c|}{ Albendazole } & \multirow{2}{*}{ Percentage of reduction } & \multicolumn{2}{|c|}{ CI 95\% } & \multirow{2}{*}{ Drench effectiveness } \\
\hline & $n$ & $\bar{X}$ epg & $n$ & $\bar{X}$ epg & & Lower & Upper & \\
\hline $\mathrm{A}$ & 15 & 1977 & 15 & 713 & 64 & -5 & 88 & Resistant \\
\hline B & 10 & 570 & 13 & 23 & 96 & 86 & 99 & Suspicious \\
\hline $\mathrm{C}$ & 11 & $250^{*}$ & 13 & 308 & -23 & -336 & 65 & Resistant \\
\hline $\mathrm{D}$ & 13 & 608 & 13 & 562 & 8 & -98 & 57 & Resistant \\
\hline $\mathrm{E}$ & 13 & $100^{*}$ & 14 & 164 & -64 & -545 & 58 & Resistant \\
\hline $\mathrm{F}$ & 14 & 2593 & 12 & 296 & 89 & 64 & 96 & Resistant \\
\hline G & 15 & 1700 & 15 & 230 & 86 & 64 & 95 & Resistant \\
\hline
\end{tabular}

* These flocks were 300 or more epg in the pre-treatment phase.

TABLE 2: Gastrointestinal nematode egg count percent reduction after treatment with ivermectin in seven flocks from Costa Rica.

\begin{tabular}{|c|c|c|c|c|c|c|c|c|}
\hline \multirow{2}{*}{ Farm } & \multicolumn{2}{|c|}{ Control } & \multicolumn{2}{|c|}{ Albendazole } & \multirow{2}{*}{ Percentage of reduction } & \multicolumn{2}{|c|}{ CI 95\% } & \multirow{2}{*}{ Drench effectiveness } \\
\hline & $n$ & $\bar{X}$ epg & $n$ & $\bar{X}$ epg & & Lower & Upper & \\
\hline A & 15 & 1977 & 15 & 317 & 84 & 49 & 95 & Resistant \\
\hline B & 10 & 570 & 12 & 46 & 92 & 80 & 97 & Resistant \\
\hline C & 11 & $250^{*}$ & 12 & 58 & 77 & 17 & 93 & Resistant \\
\hline $\mathrm{D}$ & 13 & 608 & 14 & 307 & 49 & -2 & 75 & Resistant \\
\hline E & 13 & $100^{*}$ & 14 & 7 & 93 & 28 & 99 & Resistant \\
\hline $\mathrm{F}$ & 14 & 2593 & 15 & 87 & 97 & 89 & 99 & Suspicious \\
\hline G & 15 & 1700 & 15 & 60 & 96 & 88 & 99 & Suspicious \\
\hline
\end{tabular}

* These flocks were 300 or more epg in the pre-treatment phase.

The farms included in this study met the following criteria: a minimum flock size of 60 sheep, willingness of the owner to participate, and availability of certain records and information about the flock (i.e., length of time that sheep had been at the farm, flow of animals, which anthelmintic was used) [4]. A questionnaire was used to collect information on anthelmintic control (product, frequency, and doses calculated) that was used at each farm.

Groups of young animals (3-6 months of age) were randomly allocated at each farm, by simple random sampling. The animals were not treated with anthelmintics for at least 40 days prior to the start of this study [4]. The detection of anthelmintic resistance was carried out in three phases.

Pre-Treatment. With the aim to determine the egg count prior to the beginning of the study, to be sure of having a count average higher than 300 eggs per gram (epg) a total of 10 animals per farm were sampled $[5,6]$. A sample of 10 $15 \mathrm{~g}$ of feces was collected in a plastic bag, identified, and stored at $4^{\circ} \mathrm{C}$ [5]. A total of 70 fecal samples were tested by qualitative examination using the flotation technique in a hypersaturated sugar solution (density $1: 3$ ) to detect the presence of GIN [7] at the Laboratorio de Parasitología, Escuela de Medicina Veterinaria, Universidad Nacional (LPEMV-UNA). For quantitative FEC evaluation, a modified McMaster method [7] was used.

Treatment. Three groups of 10 to 15 animals each were created, weighed with scale, identified, and treated as follows: Group A (GA) with albendazole $(4.75 \mathrm{mg} / \mathrm{kg}$, oral; Valbazen
$10 \%$, Pfizer); Group B (GB) with ivermectin $(0.2 \mathrm{mg} / \mathrm{kg}$, Ivomec, Merck Sharp \& Dohme); Control Group (CG) treated with placebo (saline solution $0.9 \%, 1 \mathrm{ml} /$ animal) [4$6,8]$. Individual samples of feces were collected by group, stored, and analyzed as described above. The identification of Strongylida infective larvae (L3) was done at the genera level using a coproculture technique with pooled samples $[6,9,10]$. A total of $100 \mathrm{~L} 3$ by each sample was identified to give the percentage.

Post-Treatment. Following the recommendation of Coles et al. [5] all animals were sampled again fifteen days after treatment, as described in the treatment phase.

Fecal egg count reduction was analyzed for each treatment group in comparison to the untreated control group. Resistance was classified as "present" if the percent reduction in FEC was less than $95 \%$ and the $95 \%$ confidence level was less than $90 \%$. If only one of the two criteria was met, resistance was classified as "suspected," according to Coles et al. [5].

Data were analyzed by descriptive statistics calculating percentages and means using Proc Freq and Proc Means of SAS ver. 9.2. To calculate the anthelmintic resistance the RESO (Anonymous, 1989) statistical package was used.

\section{Results}

Nematode anthelmintic resistance to albendazole and ivermectin was found in $86 \%(6 / 7)$ and $71 \%(5 / 7)$ of the seven sheep flocks, respectively (Tables 1 and 2). Four flocks 
TABLE 3: Anthelmintic resistance (\%) to albendazole in gastrointestinal nematodes of sheep flocks in Costa Rica.

\begin{tabular}{lccc}
\hline Nematode (\# farms) & Albendazole & Suspicious & Resistant \\
\hline Haemonchus spp. (7) & 29 & - & 41 \\
Trichostrongylus spp. & 14 & 14 & 43 \\
Cooperia spp. & 57 & 43 & 29 \\
Strongyloides spp. & - & - & 57 \\
Oesophagostomum spp. & 100 & 14 & - \\
Chabertia sp. & 86 & - \\
\hline
\end{tabular}

TABLE 4: Anthelmintic resistance to ivermectin in gastrointestinal nematodes of sheep flocks in Costa Rica.

\begin{tabular}{lccc}
\hline Nematode & & Ivermectin (\%) \\
& Susceptible & Suspicious & 29 \\
\hline Haemonchus spp. & 43 & 29 & 29 \\
Trichostrongylus spp. & - & 57 & - \\
Cooperia spp. & 43 & 43 & 43 \\
Strongyloides sp. & 14 & - & - \\
Oesophagostomum spp. & 100 & - & - \\
Chabertia sp. & 100 & -
\end{tabular}

presented resistance to both drugs $(57.1 \%)$, and none of the flocks was found to be susceptible to albendazole and ivermectin (Tables 1 and 2).

Haemonchus spp., Strongyloides sp., Trichostrongylus spp., and Cooperia spp. showed resistance to albendazole, whereas Strongyloides sp., Haemonchus spp., and Trichostrongylus spp. showed resistance to ivermectin. Haemonchus spp. (71\%) and Strongyloides sp. (43\%) presented high percentages of resistance to both albendazole and ivermectin (Tables 3 and 4). Only Oesophagostomum spp. and Chabertia sp. were susceptible to both drugs in the farms studied. This is the first time that Chabertia sp. has been reported in sheep from Costa Rica.

The questionnaire indicated that albendazole and ivermectin were used on all the farms exclusively. There were two trends of deworming frequency: three to five $(42.8 \%)$ and six or more $(57.2 \%)$ times a year. These products were alternated, applying only one of them each time. Anthelmintic doses were mainly calculated by visual estimation of animal weight $(66.7 \%)$. In all analyzed farm the chemical control was the only method of anti-parasite control used.

\section{Discussion}

This study is the first report of resistance to albendazole and ivermectin in sheep in Costa Rica.

The results indicated that $85.7 \%$ of the flocks presented resistance to albendazole, whereas $71.4 \%$ were resistant to ivermectin. The percentage of resistance to albendazole was similar to that observed in reports from Brazil (89.6\%), Paraguay (68\%), and Uruguay (86\%), but higher than that found in studies from Mexico (15.8\%) and Argentina $(40 \%)[4,8,11-13]$. In relation to ivermectin resistance, the percentage was higher with respect to that observed in Paraguay (47\%), Brazil (13\%), Argentina (6\%), Mexico
(5\%), and Uruguay $(1.2 \%)[4,8,11,12,14]$. The high percentages of resistance to both products may be due to the high frequency of treatment (six or more times a year) found for the flocks $(57.2 \%)$ and the exclusive use the chemical control. These results are in agreement with reports from Brazil and Mexico that indicated that flocks receiving more than three treatments per year rapidly developed high levels of anthelmintic resistance $[11,14,15]$. Another factor that could explain the high levels of resistance is the use of visual estimation of animal weight to calculate dosage, which may result in under- or overdosing [15].

Resistance of Haemonchus spp. to albendazole was high $(71 \%)$, similar to that found in other reports from several Latin American countries (61\%-100\%), whereas resistance to ivermectin (29\%) was comparable to that seen in Paraguay (35\%) [4, 8, 11-14, 16, 17]. Resistance of Trichostrongylus spp. to albendazole $(43 \%)$ was in agreement with the $38 \%$ reported by Maciel et al. [4] in Paraguay; however, the high level of ivermectin resistance (29\%) found in these species was different from the lower levels observed in Argentina (5\%) and Brazil (2\%) but similar to the 25\% reported in Paraguay $[4,11,12]$.

There are few reports in the literature that support the resistance of Strongyloides sp. to albendazole and ivermectin in sheep $[18,19]$.

\section{Conclusion}

In this paper, anthelmintic resistance of GIN to albendazole and ivermectin was detected for the first time in seven sheep flocks from Costa Rica. The high frequency of treatment and the use of visual estimation of animal weight to calculate the dosage may account for the high levels of anthelmintic resistance. Haemonchus spp., Strongyloides sp., and Trichostrongylus spp. were the most resistant GIN to both 
products. This is the first report of Chabertia sp. in sheep from Costa Rica.

\section{Acknowledgments}

The authors thank the Programa del Gusano Barrenador (Ministerio de Agricultura y Ganadería) and give special thanks to the sheep farmers.

\section{References}

[1] IMN (Instituto Meteorológico Nacional), Atlas Climatológico de Costa Rica, Ministerio de Agricultura y Ganadería, San José, Costa Rica, 1985.

[2] R. Maroto, Evaluación de la Resistencia antihelmíntica de nemátodos gastrointestinales en ovinos de Costa Rica, Thesis, Universidad Nacional, Heredia, Costa Rica, 2009.

[3] A. Rojas, Comparación del efecto de dos antihelminticos sobre los parásitos gastrointestinales de ovinos de la raza Barbados, Tesis licenciatura, Universidad de Costa Rica, San José, Costa Rica, 1979.

[4] S. Maciel, A. M. Giménez, C. Gaona, P. J. Waller, and J. W. Hansen, "The prevalence of anthelmintic resistance in nematode parasites of sheep in Southern Latin America: Paraguay," Veterinary Parasitology, vol. 62, no. 3-4, pp. 207212, 1996.

[5] G. C. Coles, C. Bauer, F. H. M. Borgsteede et al., "World Association for the Advancement of Veterinary Parasitology (W.A.A.V.P.) methods for the detection of anthelmintic resistance in nematodes of veterinary importance," Veterinary Parasitology, vol. 44, no. 1-2, pp. 35-44, 1992.

[6] A. Nari, J. Hansen, C. Eddi et al., "Protocolo de trabajo para la evaluación a campo de cepas potencialmente resistentes a los antihelmínticos: prueba de reducción del recuento de huevos en material fecal (FECRT)," 2004, http:// www.inta.gov.ar/producto/helminto/.

[7] M. Sloss, R. Kemp, and A. M. Zajac, Veterinary Clinical Parasitology, Iowa State University Press, Ames, Iowa, USA, 1995.

[8] A. Nari, J. Salles, A. Gil, P. J. Waller, and J. W. Hansen, "The prevalence of anthelmintic resistance in nematode parasites of sheep in Southern Latin America: Uruguay," Veterinary Parasitology, vol. 62, no. 3-4, pp. 213-222, 1996.

[9] L. W. McMurtry, M. J. Donaghy, A. Vlassoff, and P. G. C. Douch, "Distinguishing morphological features of the third larval stage of ovine Trichostrongylus spp," Veterinary Parasitology, vol. 90, no. 1-2, pp. 73-81, 2000.

[10] J. A. Van Wyk, J. Cabaret, and L. M. Michael, "Morphological identification of nematode larvae of small ruminants and cattle simplified," Veterinary Parasitology, vol. 119, no. 4, pp. 277-306, 2004.

[11] F. Echevarria, M. F. S. Borba, A. C. Pinheiro, P. J. Waller, and J. W. Hansen, "The prevalence of anthelmintic resistance in nematode parasites of sheep in Southern Latin America: Brazil," Veterinary Parasitology, vol. 62, no. 3-4, pp. 199-206, 1996.

[12] C. Eddi, J. Caracostantogolo, M. Peña et al., "The prevalence of anthelmintic resistance in nematode parasites of sheep in Southern Latin America: Argentina," Veterinary Parasitology, vol. 62, no. 3-4, pp. 189-197, 1996.

[13] J. F. J. Torres-Acosta, U. Dzul-Canche, A. J. Aguilar-Caballero, and R. I. Rodríguez-Vivas, "Prevalence of benzimidazole resistant nematodes in sheep flocks in Yucatan, Mexico," Veterinary Parasitology, vol. 114, no. 1, pp. 33-42, 2003.

[14] X. Montalvo-Aguilar, M. E. López, V. Vásquez, E. Liébano, and P. Mendoza, "Resistencia antihelmíntica de nematodos gastroentéricos en ovinos a fenbendazol e ivermectina en la región noroeste del estado de Tlaxcala," Téc. Pecu. Méx, vol. 44, pp. 81-90, 2006.

[15] FAO (Organización de las Naciones Unidas para la Agricultura y la Alimentación), Resistencia a Los Antiparasitarios: Estado Actual con Énfasis en América Latina, Dirección de Producción y Sanidad Animal de la FAO, Roma, Italy, 2003.

[16] E. Rimbaud, P. Zúñiga, M. Doña et al., "Primer diagnóstico de resistencia a levamisol y lactonas macrocíclicas en nemátodos gastrointestinales parásitos de ovinos en Nicaragua," Boletín de Parasitología, vol. 6, no. 3, 2005.

[17] E. Rimbaud, N. Pineda, J. L. Soto et al., "Primer diagnóstico de resistencia a ricobendazole y albendazole en nemátodos gastrointestinales parásitos de ovinos en Nicaragua," Boletín de Parasitología, vol. 7, no. 4, 2006.

[18] E. K. Mohamed and M. I. Al-Farwachi, "Evaluation the effect of albendazole against nematodes in sheep in Mosul," Iraqi Journal of Veterinary Sciences, vol. 22, pp. 5-7, 2008.

[19] E. A. Sczesny-Moraes, I. Bianchin, K. F. da Silva, J. B. Catto, M. R. Honer, and F. Paiva, "Resistência anti-helmíntica de nematóides gastrintestinais em ovinos, Mato Grosso do Sul," Pesquisa Veterinária Brasileira, vol. 30, no. 3, pp. 229-236, 2010. 

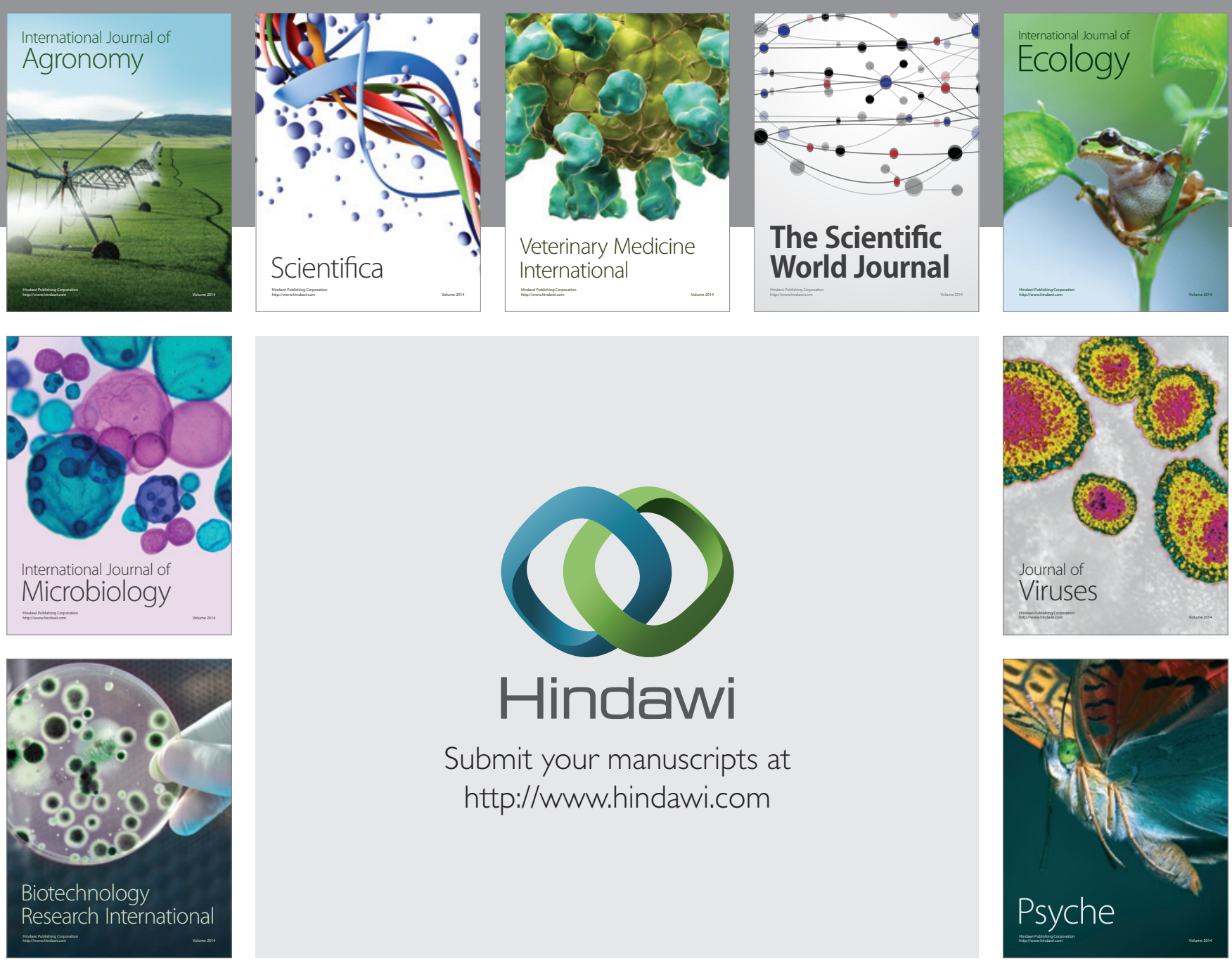

Submit your manuscripts at

http://www.hindawi.com
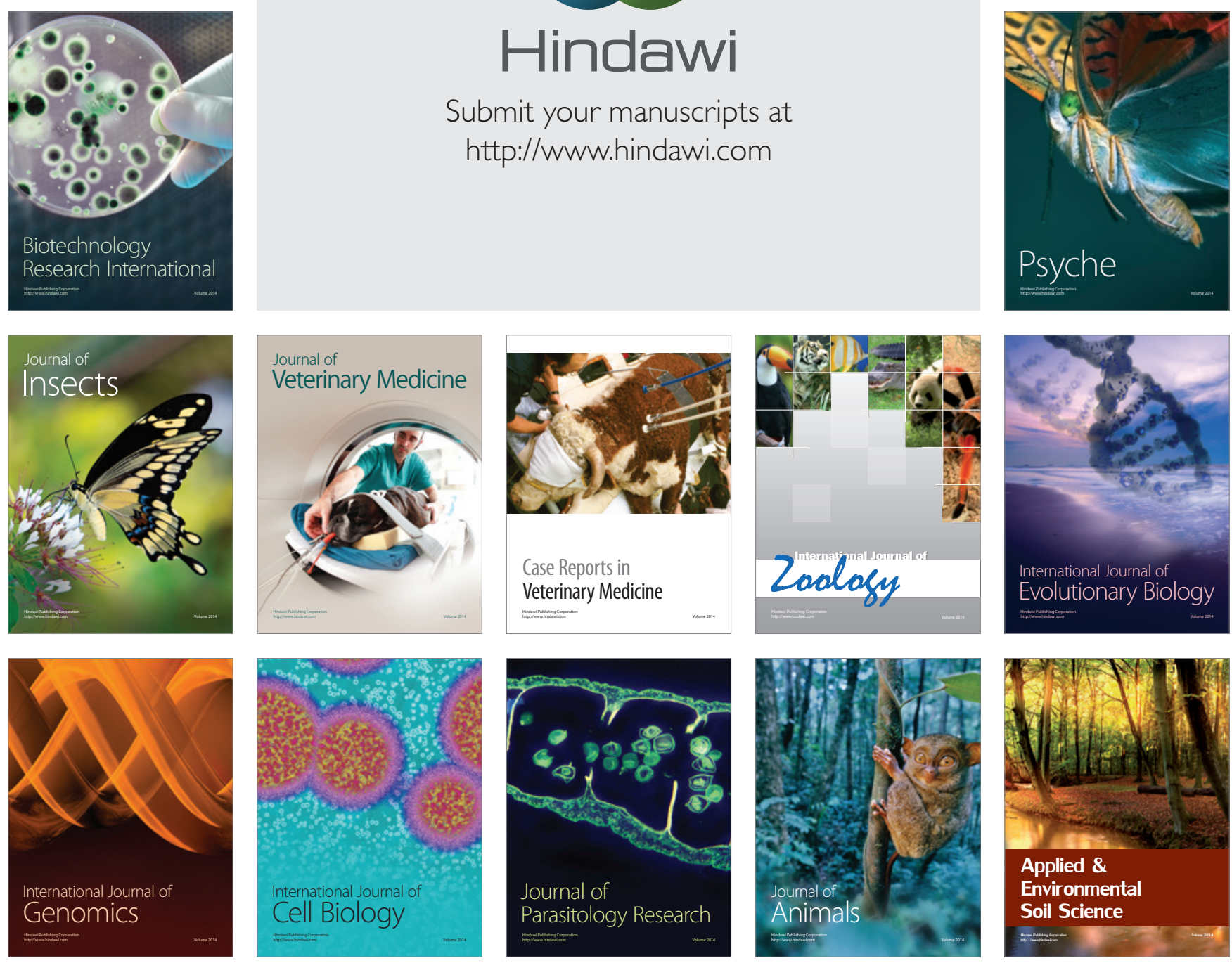